\title{
PMMA/SAN and SAN/PBT nanoblends obtained by blending extrusion using thermodynamics and microrheology basis
}

\author{
L. C. Costa $^{1 *}$, A. Ternes Neto ${ }^{1}$, E. Hage ${ }^{2}$ \\ ${ }^{1}$ Materials Science and Engineering Graduate Program, Federal University of São Carlos 13565-905 São Carlos, SP, Brazil \\ ${ }^{2}$ Department of Materials Engineering, Federal University of São Carlos 13565-905 São Carlos, SP, Brazil
}

\begin{abstract}
Styrene-Acrylonitrile (SAN) copolymer has been blended to poly(methyl methacrylate) (PMMA) and to poly(butylene terephthalate) (PBT) to obtain polymer nanoblends based on thermodynamics and microrheological aspects. PMMA/SAN and SAN/PBT blends show miscibility windows for a specific range of acrylonitrile (AN) content in the SAN copolymer. The phase diagram for both blends has been calculated using the interaction energy density parameter $B$ as function of AN content in the SAN. A critical interaction energy density parameter, $B_{\text {crit, }}$ was also calculated to find the miscibility window for both SAN blends. For some of the used SAN in the blends it was possible to obtain nanoblends as the AN content would allow $B$ values close to the $B_{\text {crit }}$. For immiscible PMMA/SAN and SAN/PBT blends the disperse particle size was predicted using suitable equations and it was observed by transmission electron microscopy (TEM). Acrylic copolymers were used as compatibilizer to modify the interfacial tension and reduce the disperse phase dimensions. The compatibilizer has shown strong effect by reducing the interfacial tension and by preventing the coalescence effect. The compatibilized blends have shown disperse particle size within the nanoscale.
\end{abstract}

Keywords: nanomaterials, polymer blends and alloys, nanoblends, compatibilization

\section{Introduction}

Nanostructured polymer blends are polymeric systems in which the dispersed-phase domains exhibit length scales of $100 \mathrm{~nm}$ or less. Usually those polymer blends are referred to as nanoblends [1]. Although, the same terminology can be found in the literature to describe mixture of inorganic nanoparticles with polymer, which should mostly be referred as nanocomposites [2]. Nanoblends have been developed to be applied in electronic, membrane, sensing probes and optical applications [3-5]. There are several approaches to obtain nanoblends. Reactive extrusion has been used to produce nanostructured polymer blends based on polyamides [1]. In situ blend polymerization has also been used to develop several kind of nanoblends [6,7]. Solution casting blending has been preferred to obtain nanoblends for those systems with poor thermo-mechanical stability to be prepared by melt mixing $[8,9]$. The most used method to prepare nanoblends is by melt blending $[10,11]$. Polymer nanoblends can be designed by two approaches, one considering thermodynamics aspects and the other one considering microrheology basis [12]. The interaction energy density parameter $(B)$ can be used to predict polymer blends phase separation with disperse domains in the nanoscale, as proposed by Paul and Bucknall [13]. B parameter is strictly related to the Flory-Huggins

\footnotetext{
${ }^{*}$ Corresponding author, e-mail: lidiane@ufscar.br

(C) BME-PT
} 
interaction parameter $\chi$ and depends on the polymers solubility parameters $\delta_{\mathrm{i}}$. There is a critical $B$ value $\left(B_{\text {crit }}\right)$ for any polymer blend which is calculated according to Equation (1):

$B_{\text {crit }}=\frac{R T}{2}\left(\sqrt{\frac{\rho_{\mathrm{A}}}{\left(\bar{M}_{\mathrm{w}}\right)_{\mathrm{A}}}}+\sqrt{\frac{\rho_{\mathrm{B}}}{\left(\bar{M}_{\mathrm{w}}\right)_{\mathrm{B}}}}\right)^{2}$

where, $\rho_{\mathrm{A}}, \rho_{\mathrm{B}}$ and $\left(\bar{M}_{\mathrm{w}}\right)_{\mathrm{A}},\left(\bar{M}_{\mathrm{w}}\right)_{\mathrm{B}}$ represent densities and the weight average molecular weights of polymers $A$ an $B$, respectively. In addition, $R$ and $T$ represent gas constant and absolute temperature, respectively. For those blends whose $B$ value is lower than $B_{\text {crit }}$ the final state of mixing is miscible. On the other hand, those which $B$ is larger than $B_{\text {crit }}$ the final mixing states are immiscible. In addition, when $B$ is larger than $B_{\text {crit }}$, but the difference among them is small, the disperse particle size may become small enough to reach nanoscale. By choosing adequate polymer pairs it is possible to vary $B$ values below and above Bcrit to obtain miscible and immiscible polymer blends. Poly(methyl methacrylate)/styreneacrylonitrile copolymer blends, PMMA/SAN, have been studied because it allows to have miscible and immiscible blends depending on the acrylonitrile (AN) content in the SAN [14-16]. There is an AN content limit in the SAN above which PMMA/SAN blends become immiscible with disperse phase in the range of nanoparticles. That is referred to as miscibility copolymer composition window. Paul and Barlow [17] have shown how to find the miscibility window for copolymer blends using a binary interaction model based in the interaction energy density parameter $B$. Miscibility windows for PMMA/SAN have been set for SAN copolymer containing from 9 to $35 \mathrm{wt} \%$ of acrylonitrile (AN) [18], depending on the SAN molecular weight. Higashida et al. [19] have shown the same trend for PMMA/SAN blends basing on Flory-Huggins parameter $\chi$, however by increasing temperature of PMMA/SAN miscible blend it was possible to have a lower critical solution temperature (LCST). Shimomai et al. [20] have used the equation of state theory to show the PMMA/ SAN miscibility window and have also predicted a LCST by increasing temperature. By changing the AN content in the SAN copolymer the $B$ interaction parameter of the PMMA/SAN blend can be increased just above the $B_{\text {crit }}$ value reaching an immiscible state. However, the disperse phase may show nanoscale domains size which allow to obtain nanoblends. This is one of the objectives of the present paper.
As described in the paper nanostructured blends or nanoblends can be obtained by choosing the interaction energy density paramenter $B$ just above the critical $B$ value ( $\left.B_{\text {crit }}\right)$. That approach is based on the Thermodynamics of a homopolymer and a copolymer mixture. On the other hand, when $B$ for any polymer blend is well above the $B_{\text {crit, }}$ nanostructured blends can be obtained by choosing adequate microrheological parameters for the blend such as: disperse and matrix phases viscosity ratio; shear and extensional flow conditions and interfacial tension or energy. All those parameters affect the final particle size of the blend disperse phase. In addition, sometimes compatibilization is necessary to reduce the interfacial tension and to prevent the coalescence for higher disperse phase content in the polymer blend [21]. One of main rheological parameters is the viscosity ratio between the liquids, which can be determined by Equation (2) [22]:

$\eta_{\mathrm{r}}=\frac{\eta_{\mathrm{d}}}{\eta_{\mathrm{m}}}$

where $\eta_{\mathrm{d}}$ and $\eta_{\mathrm{m}}$ are the viscosity values for the disperse and matrix phase at the mixing temperature, respectively. For simple shear flow at small Newtonian liquid deformations, the particle diameter $D$, due the drop breakup, can be determined by balancing interfacial tension $(\Gamma)$ and shear forces $\left(\dot{\gamma} \eta_{\mathrm{m}}\right)$, as shown in Equation (3):

$$
D=\frac{4 \Gamma\left(\eta_{\mathrm{r}}+1\right)}{\dot{\gamma} \eta_{\mathrm{m}}\left(\frac{19}{4} \eta_{\mathrm{r}}+4\right)}
$$

where $\dot{\gamma}$ is the shear rate and $\eta_{\mathrm{m}}$ is the matrix phase viscosity. The above equation is valid for $\eta_{\mathrm{r}}<2.5$. $\mathrm{Wu}$ [23] has modified it to represent drop breakup in polymer blends. Thus the previous equation becomes Equation (4):

$D=\frac{4 \Gamma\left(\eta_{\mathrm{r}}\right)^{ \pm 0.84}}{\dot{\gamma} \eta_{\mathrm{m}}}$

where 0.84 is a empirical exponent and the plus (+) sign applies for $\eta_{\mathrm{r}}>1$, while minus (-) sign applies to $\eta_{\mathrm{r}}<1$. Equation (4) is applied to compositions lower than $15 \mathrm{wt} \%$ of the disperse phase and $\dot{\gamma}$ close to $100 \mathrm{~s}^{-1}$. In addition, Sundararaj and Macosko [22] have extended it to include viscoelastic effects during the polymeric drop breakup. It was established a critical capillary number value, $C_{\text {acrit }}$, above which drop breakup for polymer blends will occur leading 
to disperse particle diameter size $D$, estimated by Equation (5):

$$
D>\frac{2 \Gamma C_{\text {acrit }}}{\left(\eta_{\mathrm{m}} \dot{\gamma}-N_{1}\right)}
$$

where, $N_{1}$ represents the first normal stress difference due to the elastic forces during polymer mixing. $C_{\text {acrit }}$ can be estimated as approximately 0.5 for $0.1<\eta_{\mathrm{r}}<1$. By optimizing shear and extensional flow conditions, as well as, reducing as much as possible the interfacial energy, $\Gamma$, it is possible to obtain disperse particle size in the range of nanoscale. In addition, it is necessary to prevent as much as possible the particles coalescence, which can be done through compatibilization and for lower contents of the disperse phase component. Li and Shimizu [10] have obtained nanoblends from poly(vinylidene fluoride) (PVDF) by melt mixing. Polyamide 11 (PA11) particle size in the range of 20 to $100 \mathrm{~nm}$ was obtained at very high shear. Similar morphology was obtained for acrylic rubber (ACM) in PVDF blends [24]. Lumlong et al. [25] have obtained very small disperse particles for poly (butylene terephthalate)/SAN blends, PBT/SAN, under certain shear conditions and for lower disperse phase content.

The main contribution of this work is to obtain nanoblends by choosing either adequate thermodynamics parameters such as the interaction energy density parameter $B$ or adequate microrheological parameters such as viscosity ratio and interfacial energy. The latter one can be reached by using compatibilizers. There are few works about nanoblends in the literature obtained from melt mixing and none using that approach.

\section{Experimental}

\subsection{Materials}

PMMA was supplied by UNIGEL, Brazil, as Acrigel ${ }^{\circledR}$ DHLEP, SAN copolymer samples were supplied by BASF, Brazil, as LURAN ${ }^{\circledR} 358 \mathrm{~N}$ and $388 \mathrm{~S}$, PBT was supplied by SABIC Innovative Plastics, Brazil, as Valox ${ }^{\circledR} 325$. Table 1 shows the properties of the materials used in this study. An acrylic compatibilizer based on methyl methacrylate (MMA), glycidyl methacrylate (GMA) and ethyl acrylate (EA) comonomers was synthesized through bulk copolymerization at $60^{\circ} \mathrm{C}$ for 1 hour. MMA was supplied by Sheet Cril, Brazil, while GMA and EA were supplied by Sigma-Aldrich, Brazil. Azobisisobutyronitrile (AIBN), used as initiator, was by DuPont Brazil as Vazo ${ }^{\circledR}$ 64. MMA comonomer was previously distilled under vacuum. The acrylic copolymer, referred as MGE, was obtained with the composition MMA $88 \mathrm{wt} \%$, GMA $10 \mathrm{wt} \%$ and EA $2 \mathrm{wt} \%$, as used by Hale et al. [26]. EA comonomer was mainly used in the copolymer as a stabilizer to prevent molecular unzipping scissions. Two MGE samples were synthesized to give low and higher molecular weight samples, MGE 1 and MGE 2 respectively. Table 1 shows the main characteristics of all materials used in this study.

\subsection{Processing conditions}

All polymer blends were prepared by melt mixing using a co-rotated intermeshing twin screw $19 \mathrm{~mm}$

Table 1. Characteristics of the materials used in this study.

\begin{tabular}{|c|c|c|c|c|c|c|}
\hline Materials & $\begin{array}{c}\text { MFI } \\
{[\mathrm{g} / 10 \mathrm{~min}]^{\mathrm{a}}}\end{array}$ & $\begin{array}{c}\overline{\mathbf{M}}_{\mathrm{n}} \\
{[\mathrm{g} / \mathrm{mole}]^{\mathrm{b}}}\end{array}$ & $\begin{array}{c}\overline{\mathbf{M}}_{\mathrm{w}} \\
{\left[\mathrm{g} / \mathrm{mole}^{\mathrm{b}}\right.}\end{array}$ & $\frac{\overline{\mathbf{M}}_{\mathrm{w}}}{\overline{\mathbf{M}}_{\mathrm{n}}}$ & $\begin{array}{c}\text { AN } \\
{[\%]^{\mathrm{e}}}\end{array}$ & $\begin{array}{c}{[\mathrm{COOH}]} \\
{[\mathrm{meq} /(\mathrm{K} \cdot \mathrm{g})]^{\mathrm{f}}}\end{array}$ \\
\hline PMMA & 4.6 & 75670 & 113350 & 1.5 & - & - \\
\hline $\begin{array}{c}\text { SAN } 24 \\
\text { (LURAN 358N) }\end{array}$ & 7.5 & 107440 & 156860 & 1.5 & 24 & - \\
\hline $\begin{array}{c}\text { SAN 31 } \\
\text { (LURAN 388S) }\end{array}$ & 2.6 & 166050 & 321200 & 1.9 & 31 & - \\
\hline $\begin{array}{c}\text { PBT } \\
\text { (Valox 325) }\end{array}$ & 14.0 & $39175^{c}$ & $45000^{\mathrm{d}}$ & - & - & 45.3 \\
\hline MGE 1 & - & 13950 & 81810 & 5.9 & - & - \\
\hline MGE 2 & - & 26370 & 102720 & 3.9 & - & - \\
\hline
\end{tabular}

${ }^{\mathrm{a}} \mathrm{ASTM}$ D1238: $230^{\circ} \mathrm{C}$ and $3.8 \mathrm{~kg}$;

${ }^{\mathrm{b}} \mathrm{GPC}$ : THF and $40^{\circ} \mathrm{C}$;

${ }^{c}$ Viscosimetry: Borman method [27];

${ }^{\mathrm{d}}$ Based on polycondensation molecular weight polydispersivity index;

eElementar analysis;

fitration: Pohl method [28] 
diameter extruder from B\&P Process Equipment and Systems, U.S.A., model MP19, with $L / D$ as 25. All materials were previously dried under vacuum at $60^{\circ} \mathrm{C}$. The PMMA/SAN blends were melt blended in the extruder using a temperature profile from 180 to $220^{\circ} \mathrm{C}$ and $170 \mathrm{rpm}$ as screw speed, while the SAN/PBT blends were mixed from 220 to $240^{\circ} \mathrm{C}$ at $140 \mathrm{rpm}$ and $200 \mathrm{rpm}$. Both polymer blends were dried for 12 hours at $60^{\circ} \mathrm{C}$ before to be injection molded as testing specimens. The temperature profile for the injection molding was from 210 to $240^{\circ} \mathrm{C}$. Table 2 shows all the prepared PMMA/ SAN and SAN/PBT blends compositions.

\subsection{Characterization}

The blends morphology was observed by transmission electron microscope (TEM), PHILIPS, model CM120, Oregon. All samples were ultracryomicrotomed at $-60^{\circ} \mathrm{C}$ with section thickness in the range of 30 to $50 \mathrm{~nm}$. The sections of both kinds of blends were stained by ruthenium tetroxide, $\mathrm{RuO}_{4}$, vapor. All the micrographs taken from the TEM had their particle size analysis made by Image-Pro Plus. At least 300 particles were considered in the image analysis of each sample. For the PMMA/SAN blends the average particle size and its distribution were obtained using equivalent diameter particle size and considering the projected disperse phase area. On the other hand, for SAN/PBT blends ellipses were considered to measure the shorter axis $(B)$. In addition, the equivalent diameter was also calculated from the particles projected area $\left(D_{\mathrm{n}}\right)$.

Shear viscosity data for the studied materials was obtained by capillary rheometry using an INSTRON capillary rheometer, model 4467, Massachusetts, U.S.A. All the viscosity measurements were done at $240^{\circ} \mathrm{C}$, using a capillary die with 33 as $L / D$. The shear rate was swept from 100 to $30000 \mathrm{~s}^{-1}$. The interfacial tension data used for SAN 24/PBT blends were obtained from parallel plate rheometry. Viscosity values were obtained under rotational and oscillatory conditions as a function of shear rates and frequency. An ARES rheometer from Rheometric Scientific, model strain control, U.S.A., was used with a $25 \mathrm{~mm}$ parallel plate diameter, with shear rate in the range of 0.01 to $100 \mathrm{~s}^{-1}$ and oscillatory frequency in the range of 0.01 to $500 \mathrm{rads} / \mathrm{s}$. The distance between plates was fixed as $6 \mathrm{~mm}$ and the strain amplitude was set in the linear viscoelastic range. All measurements were done at $240^{\circ} \mathrm{C}$ under dry inert nitrogen gas flow.

\section{Results and discussion}

Considering the PMMA/SAN and SAN/PBT blends, the interaction energy density parameter $B$ was calculated as a function of the AN content in the SAN using Equation (6) for each one and plotted as function of AN content in Figure 1. The $B_{\text {crit }}$ value, calculated from Equation (1), was also plotted in Figure 1 to show the miscibility windows for SAN blends. Parameter $B$ for a homopolymer 1 (PMMA or PBT)/copolymer 2-3 (copolymer S-AN) blend can be calculated by Equation (6):

$B=B_{12} \varphi_{2}^{\prime}+B_{13} \varphi_{3}^{\prime}-B_{23} \varphi_{2}^{\prime} \varphi_{3}^{\prime}$

where $B_{12}$ represents the interaction between monomer from homopolymer 1 and comonomer 2 from copolymer 2-3. In the same way $B_{13}$ represents interaction between monomer from homopolymer 1 and comonomer 3 from copolymer 2-3. $B_{23}$ represents the interaction between the comonomers from copolymer 2-3. On the other hand, $\varphi_{2}^{\prime}$ and $\varphi_{3}^{\prime}$ represent the comonomer volume fraction contents 2 and 3 of the copolymer 2-3, respectively. For the PMMA/ SAN blends $B_{12}$ and $B_{13}$ are represented by the interaction parameters $B_{\mathrm{MMA}-\mathrm{S}}$ and $B_{\mathrm{MMA}-\mathrm{AN}}$, respectively, while $B_{23}$ is represented by $B_{\mathrm{S}-\mathrm{AN}}$. For SAN/ PBT blends $B_{12}$ and $B_{13}$ are represented by the interaction parameters $B_{\mathrm{PBT}-\mathrm{S}}$ and $B_{\mathrm{PBT}-\mathrm{AN}}$, respectively, while $B_{23}$ is represented by $B_{\mathrm{S}-\mathrm{AN}}$. The $B_{\mathrm{ij}}$ values for each interaction pair are shown in Table 3. On the other hand, $\varphi_{2}^{\prime}$ and $\varphi_{3}^{\prime}$ represents the weight fraction content of styrene (S) and of acrylonitrile (AN) comonomers in the SAN copolymer. Calculations were done considering volume fraction close to the weight fraction because all components density is quite close to $1 \mathrm{~g} / \mathrm{cm}^{3}$.

Table 2. Polymer blends formulations prepared by extrusion and injection molded

\begin{tabular}{|c|c|c|c|c|}
\hline Materials & $\begin{array}{c}\text { PMMA/SAN 24 } \\
{[\mathbf{w t \% / w t \% ]}}\end{array}$ & $\begin{array}{c}\text { PMMA/SAN 24/MGE 1 } \\
{[\mathbf{w t} \% / \mathbf{w t} \% / \mathbf{w t} \%]}\end{array}$ & $\begin{array}{c}\text { SAN 24/PBT } \\
{[\mathbf{w t} \% / \mathbf{w t} \%]}\end{array}$ & $\begin{array}{c}\text { SAN 24/PBT/MGE 2 } \\
{[\mathbf{w t} \% / \mathbf{w t} \% / \mathbf{w t} \%]}\end{array}$ \\
\hline SAN 24 & {$[99 / 1] ;[97 / 3] ;[95 / 5] ;[90 / 10]$} & {$[94 / 1 / 5] ;[92 / 3 / 5] ;[90 / 5 / 5] ;[85 / 10 / 5]$} & {$[90 / 10]$} & {$[94.5 / 3 / 2.5] ;[90.9 / 5 / 4.1] ;[81.8 / 10 / 8.2]$} \\
\hline SAN 31 & {$[99 / 1] ;[97 / 3] ;[95 / 5] ;[90 / 10]$} & {$[94 / 1 / 5] ;[92 / 3 / 5] ;[90 / 5 / 5] ;[85 / 10 / 5]$} & & \\
\hline
\end{tabular}


Table 3. Binary interaction energy density $B_{\mathrm{ij}}$ for styrene (S), acrylonitrile (AN), methyl methacrylate (MMA) and poly(butylene terephthalate) (PBT) pair combinations estimated at $200^{\circ} \mathrm{C}$ for PMMA/SAN blends and at $240^{\circ} \mathrm{C}$ for SAN/PBT blends [29]

\begin{tabular}{|l|c|}
\hline \multicolumn{1}{|c|}{ Pairs ij } & $\begin{array}{c}\mathbf{B}_{\mathbf{i j}} \\
{\left[\mathbf{c a l} / \mathbf{c m}^{3}\right]}\end{array}$ \\
\hline S-AN $\left(200^{\circ} \mathrm{C}\right)$ & 7.00 \\
\hline S-MMA & 0.26 \\
\hline MMA-AN & 4.45 \\
\hline S-PBT & 0.51 \\
\hline AN-PBT & 7.40 \\
\hline S-AN $\left(240^{\circ} \mathrm{C}\right)$ & 6.86 \\
\hline
\end{tabular}

Table 4 shows the $B_{\text {crit }}$ values for both PMMA/SAN blends, calculated using Equation (1). The interceptions of those values with the $B$ parameter curve, as shown in Figure 1, determines the range of AN content in the SAN copolymer for the miscibility window. For the PMMA/SAN blend the range of the miscibility window is set from 13.0 up to 27.1 AN wt $\%$, while for the SAN/PBT blend the miscibility window stays between 17.8 and $21.9 \mathrm{AN} \mathrm{wt} \%$. Considering SAN 24 and SAN 31 as copolymer components in the PMMA/SAN blends, according to the miscibility window, PMMA/SAN 24 is miscible while PMMA/SAN 31 is immiscible. On the other hand, using SAN 24 as copolymer component in the SAN/PBT blends, those blends are immiscible. In addition, for PMMA/SAN 31 the $B$ value, $0.0619 \mathrm{cal} / \mathrm{cm}^{3}$, is close to the $B_{\text {crit }}, 0.0090 \mathrm{cal} / \mathrm{cm}^{3}$, from which it might expected to obtain PMMA/SAN nanoblends, as proposed by Paul and Bucknall [13]. The same expectation can be extended to the SAN 24/

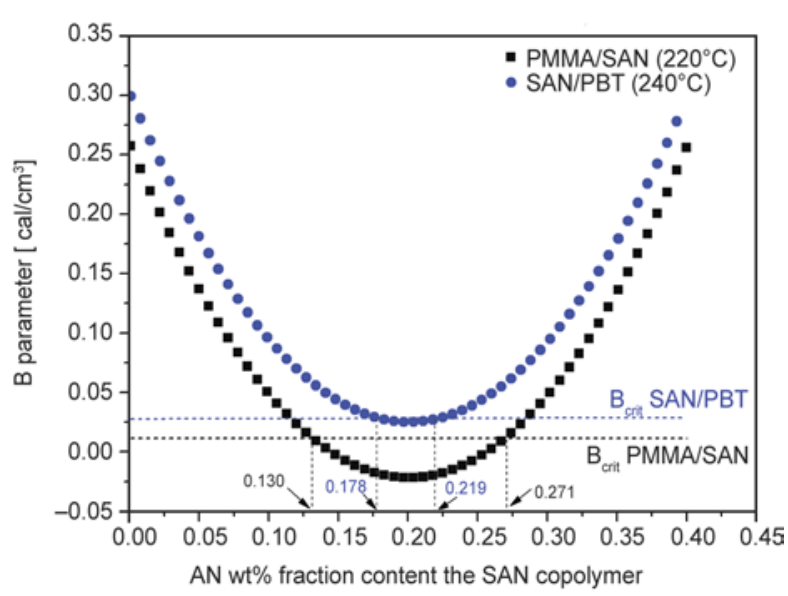

Figure 1. Interaction energy density parameter $B$ for the PMMA/SAN and SAN/PBT blends as function of acrylonitrile (AN) content in the SAN copolymer. $B_{\text {crit, }}$, calculated by Equation (1), has been plotted as dash straight lines to show the miscibility window for both blends.
Table 4. Critical interaction energy density parameter ( $\left.B_{\text {crit }}\right)$ for both PMMA/SAN and SAN/PBT blends calculated at $200^{\circ} \mathrm{C}$ and $240^{\circ} \mathrm{C}$, respectively

\begin{tabular}{|l|c|}
\hline \multicolumn{1}{|c|}{ SAN blends } & $\begin{array}{c}\mathbf{B}_{\text {crit }} \\
{\left[\mathbf{c a l} / \mathbf{c m}^{3}\right]}\end{array}$ \\
\hline PMMA/SAN 24 & $0.0111^{\mathrm{a}}$ \\
\hline PMMA/SAN 31 & $0.0090^{\mathrm{a}}$ \\
\hline SAN 24/PBT & $0.0277^{\mathrm{b}}$ \\
\hline
\end{tabular}

${ }^{a}$ Values calculated for the PMMA and SAN densities at $200^{\circ} \mathrm{C}$

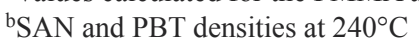

PBT blends in which the $B$ value, $0.0351 \mathrm{cal} / \mathrm{cm}^{3}$, is even closer to its $B_{\text {crit }}, 0.0277 \mathrm{cal} / \mathrm{cm}^{3}$.

Figure 2 shows the TEM morphologies for PMMA/ SAN 24 miscible blend. It can be observed that PMMA/SAN 24 blend stays quite as a homogeneous single phase, thereby representing a miscible blend. The $\mathrm{RuO}_{4}$ interacts strongly with the aromatic rings from the styrene comonomer of SAN. Therefore, the dark spots observed in the images are assigned to the SAN copolymer. Figure 3 shows PMMA/SAN 31 blends TEM micrographs at different compositions. Phase separation can be observed for the PMMA/SAN 31 blends, where the dark domains are SAN $31 \mathrm{RuO}_{4}$ stained particles. All morphological observations seem to agree with the phase behavior which has been predicted by the thermodynamics analysis from Figure 1. Most of the SAN 31 disperse particles has size below $100 \mathrm{~nm}$,

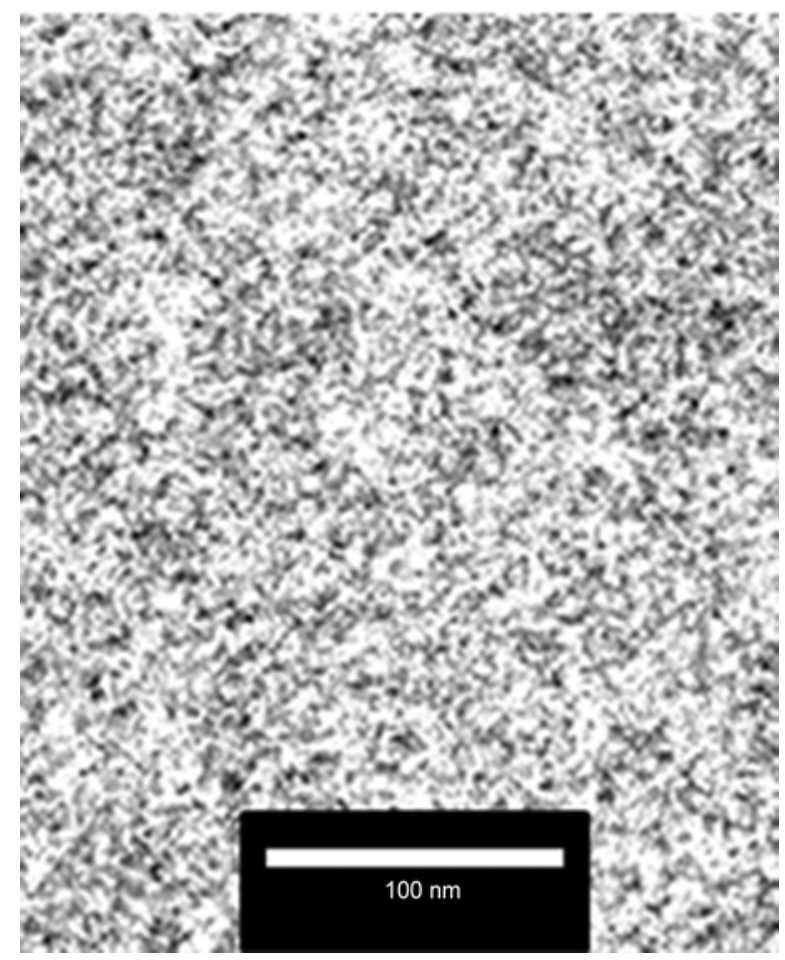

Figure 2. TEM micrographs obtained for PMMA/SAN 24 blend 90/10, as injection molded 

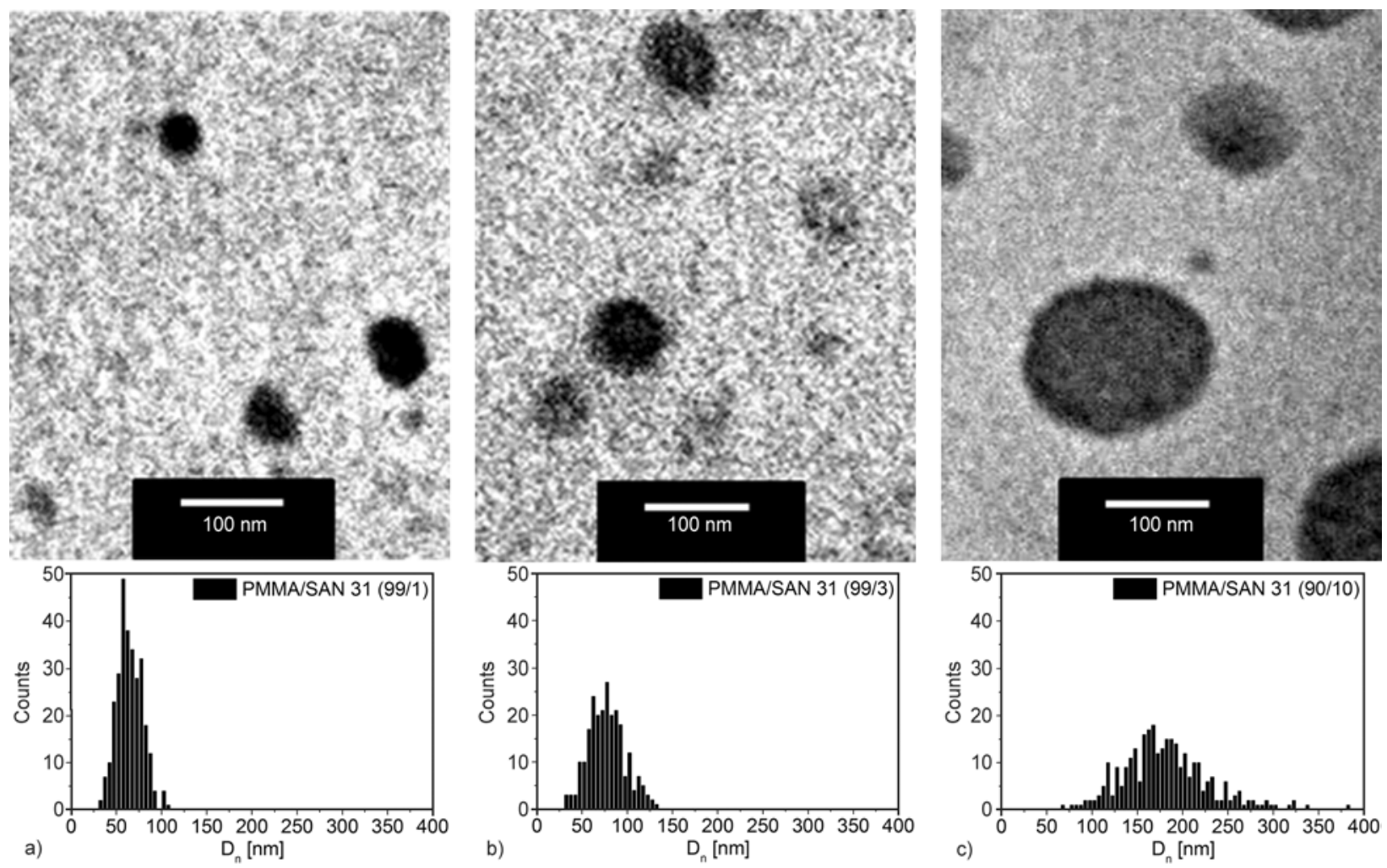

Figure 3. PMMA/SAN 31 blend TEM micrographs and particle size distribution histograms at different compositions, as injection molded: (a) $99 / 1$; (b) $97 / 3$; (c) $90 / 10$

as shown in Figure 3. PMMA/SAN 31 nanoblends were mainly obtained for lower SAN 31 contents as can be observed from the respective particle size distribution histograms of the PMMA/SAN 31 nanoblend, as shown in Figure 3. At lower SAN 31 contents most of its particles are below $100 \mathrm{~nm}$. The SAN 31 particle average size, obtained from the histograms in Figure 3, is shown in Table 5. As proposed by Paul and Bucknall [13] the parameter energy density $B_{\text {PMMA/SAN } 31}$ is small enough, compared to the $B_{\text {crit }}$, that very small particles can be obtained within the nanoscale size. As previously cited, the PMMA/SAN blends were prepared by melt mixing and injection molded. Most of the thermodynamics applied to analyze polymer-polymer miscibility is based on the mixing state equilibrium. On the other hand, polymer blending obtained by melt extrusion is well far away from the thermody-

Table 5. SAN 31 disperse phase average particle size for the PMMA/SAN 31 blends, as injection molded

\begin{tabular}{|l|c|c|}
\hline PMMA/SAN 31 & $\begin{array}{c}\text { Average equivalent } \\
\text { diameter } \\
{[\mathbf{n m}]}\end{array}$ & $\begin{array}{c}\text { Standard deviation } \\
\text { [nm] }\end{array}$ \\
\hline $99 / 1$ & 63 & \pm 14 \\
\hline $97 / 3$ & 77 & \pm 20 \\
\hline $90 / 10$ & 181 & \pm 48 \\
\hline
\end{tabular}

namics equilibrium due to the unstable temperature and pressure. Therefore it is surprising that the predicted thermodynamic conditions to produce nanoblends can be applied within the melt blending conditions and still obtains nanoparticles as expected. Even so, the PMMA/SAN 31 blend morphology gives results as been in the equilibrium state of mixing, at least for lower SAN 31 contents. As the amount of SAN 31 is increased in the blend, the coalescence mechanism becomes more pronounceable leading to less stable mixing, as predicted by Tokita [30].

The blend viscosity ratio can be obtained for PMMA/ SAN and SAN/PBT blends from capillary rheometry, as shown in Figure 4. All blend components have a strong pseudoplastic behavior. According to Equation (2) the viscosity ratio $\eta_{\mathrm{r}}$ can be calculated for any shear rate for all studied blends in this work. The PMMA matrix viscosity and the SAN 31/ PMMA viscosity ratio can be observed in Table 6 for several shear rates. That viscosity ratio is close to 1 . As consequence a good SAN 31 dispersion in the PMMA matrix would be expected. According to Equation (4) the particle diameter $D$ would only depends on the interfacial tension and the rheological forces. As the shear rate increases the rheologi- 


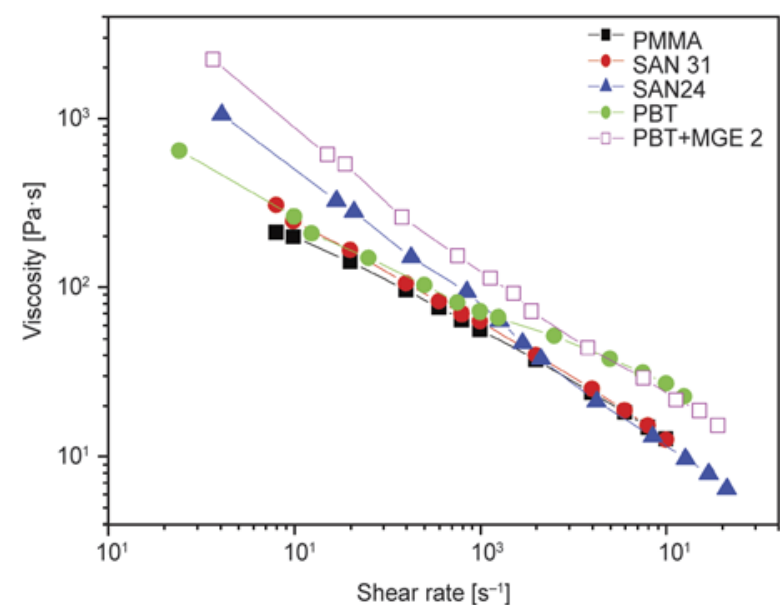

Figure 4. Apparent viscosity curves obtained from capillary rheometry for PMMA, SAN 24, SAN 31, $\mathrm{PBT}$ and $\mathrm{PBT}+\mathrm{MGE} 2$ measured at $240^{\circ} \mathrm{C}$

Table 6. Capillary viscosity for PMMA, SAN and viscosity ratio for their blends

\begin{tabular}{|c|c|c|c|c|}
\hline \multirow{2}{*}{$\begin{array}{l}\text { Shear rate } \\
\qquad\left[\mathrm{s}^{-1}\right]\end{array}$} & \multicolumn{2}{|c|}{$\begin{array}{c}\text { Shear viscosity } \\
{[\mathrm{Pa} \cdot \mathrm{s}]}\end{array}$} & \multirow{2}{*}{$\begin{array}{c}\text { Viscosity } \\
\text { ratio } \\
\eta_{\text {SAN }} \\
\eta_{\text {PMMA }}\end{array}$} & \multirow{2}{*}{$\begin{array}{l}\text { Rheological } \\
\text { force, } \dot{\gamma} \eta_{\mathrm{m}} \\
\quad[\mathrm{Pa}]\end{array}$} \\
\hline & PMMA & SAN 31 & & \\
\hline 100 & 196 & 240 & 1.22 & 19600 \\
\hline 200 & 142 & 164 & 1.15 & 28400 \\
\hline 300 & 112 & 126 & 1.13 & 33600 \\
\hline 500 & 83 & 92 & 1.11 & 41500 \\
\hline 1000 & 58 & 63 & 1.09 & 58000 \\
\hline 2000 & 38 & 40 & 1.05 & 76000 \\
\hline 5000 & 21 & 22 & 1.04 & 105000 \\
\hline
\end{tabular}

cal force increases, which would reduce. The interfacial tension $v_{12}$ can be calculated by the harmonic average equation (Equation (7)) [31]:

$\nu_{12}=\nu_{1}+\nu_{2}-\frac{4 \nu_{1}^{\mathrm{d}} \nu_{2}^{\mathrm{d}}}{\nu_{1}^{\mathrm{d}}+\nu_{2}^{\mathrm{d}}}-\frac{4 \nu_{1}^{\mathrm{p}} \nu_{2}^{\mathrm{p}}}{\nu_{1}^{\mathrm{p}}+\nu_{2}^{\mathrm{p}}}$

where $v_{1}$ and $v_{2}$ are the surface tension, while $v_{1}^{\mathrm{d}}$ and $v_{2}^{\mathrm{d}}$ are the non-polar surface tension components and $v_{1}^{\mathrm{p}}$ and $v_{2}^{\mathrm{p}}$ are the polar surface tension for components 1 and 2 of the blend, respectively. The surface tensions $v_{\mathrm{i}}$ for PMMA and SAN 31 at $20^{\circ} \mathrm{C}$ was obtained from $\mathrm{Wu}$ [23] and extrapolated for $220^{\circ} \mathrm{C}$ according to Ito et al. [32]. Both values are 24.4 and $25.1 \mathrm{mN} / \mathrm{m}$, respectively. The polar surface tensions $v_{\mathrm{i}}^{\mathrm{p}}$ were calculated for PMMA and SAN 31 by Equation (8) as 6.85 and $2.87 \mathrm{mN} / \mathrm{m}$, respectively:

$v_{\mathrm{i}}^{\mathrm{p}}=X_{\mathrm{i}}^{\mathrm{p}} v_{\mathrm{i}}$

where $X_{\mathrm{i}}^{\mathrm{p}}$ is the polarity for both components, which are 0.280 and 0.110 for PMMA and SAN 31, respectively. The $v_{i}^{\mathrm{d}}$ is obtained as $\left(1-v_{i}^{\mathrm{p}}\right)$ and it is $17.53 \mathrm{mN} / \mathrm{m}$ for PMMA and $23.23 \mathrm{mN} / \mathrm{m}$ for SAN 31. As result, $v_{12}$ can be calculated as $1.3 \mathrm{mN} / \mathrm{m}$ for the PMMA/SAN 31 blend. On the other hand, the PMMA/SAN 31 viscosity ratio can be chosen as 1.09 at shear rate close to $1000 \mathrm{~s}^{-1}$, because the used range of shear rates where the PMMA/SAN melt blending was prepared has been calculated for the twin screw extruder running at $170 \mathrm{rpm}$ [33]. Thus, the minimum shear rate occurs in the conveying screw section at $51 \mathrm{~s}^{-1}$, while the maximum shear rate is in the kneading screw section which is $1127 \mathrm{~s}^{-1}$. Considering that most of the particle breaking occurs between the kneading elements, the particle size can be estimated from Equation (4) by using the power index as +0.84 . Thus the particle size $D$ was estimated as $96.8 \mathrm{~nm}$, which is within the values of $D$ shown in Table 5. However, the estimated $D$ through Equation (4) has not included viscoelastic effects on the drop breaking.

MGE 1 copolymer was used to modify the interfacial tension for PMMA/SAN 31 blends. Figure 5 shows the blend morphology for the ternary PMMA/ SAN 31/MGE 1 blends.

The interface has changed from a sharp transition to a white halo around the SAN disperse phase, as indicated by the black arrows in the micrographs, which can be considered as an interphase. That interfacial region is certainly a MGE rich phase because it cannot be stained by $\mathrm{RuO}_{4}$. MGE 1 has no aromatic ring in its chemical structure to be stained by $\mathrm{RuO}_{4}$. The presence of MGE 1 has prevented the coalescence effect because it has allowed a reduction in the SAN 31 average particle size as shown in Figure 6. The SAN particle size has shown a significant reduction mainly for higher contents where the coalescence is more effective to increase the particle size. As result all SAN 31 contents have shown the average particle size in the nanoscale range. Gan and Paul [34] has predicted phase separation for SAN/MGE blends at temperatures above $185^{\circ} \mathrm{C}$, when SAN has $32.3 \mathrm{wt} \%$ of AN and MGE has between 8 and $14 \mathrm{wt} \%$ of GMA. Therefore it could be expected that MGE 1, containing $10 \mathrm{wt} \%$ of GMA, would be immiscible with SAN 31 at temperatures above $185^{\circ} \mathrm{C}$. In addition, the blending temperature in the extruder was around $220^{\circ} \mathrm{C}$ and the injection molding temperature was $240^{\circ} \mathrm{C}$. Both temperatures are well above $185^{\circ} \mathrm{C}$ established by the 


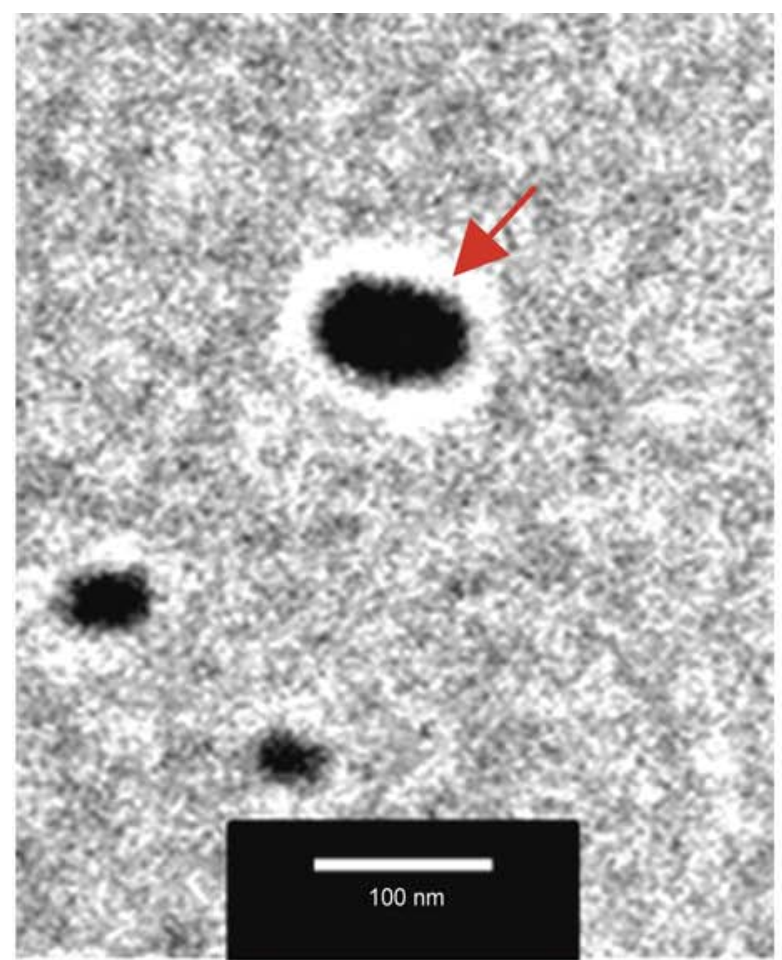

a)

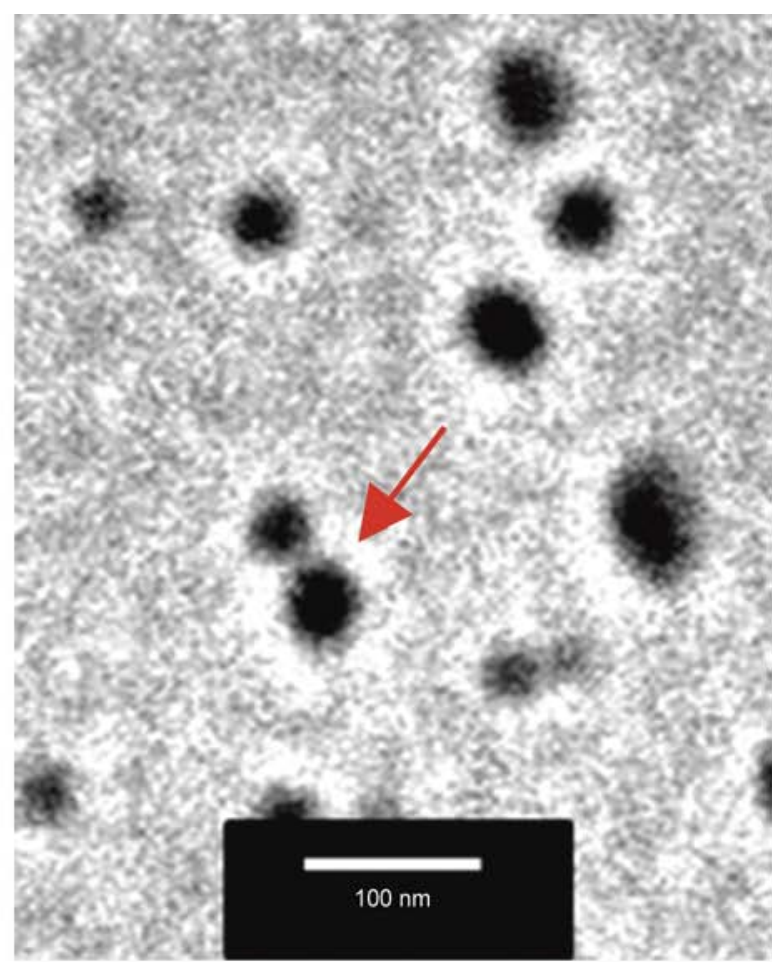

b)

Figure 5. TEM micrographs for melt mixed PMMA/SAN 31/MGE 1 blends, injection molded at 240 ${ }^{\circ}$ : (a) 94/1/5; (b) $92 / 3 / 5$

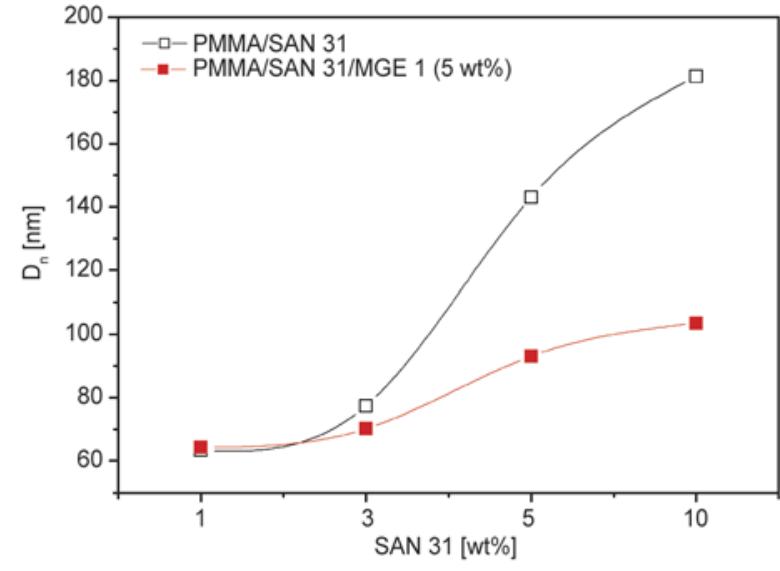

Figure 6. SAN 31 average particle size $\left(D_{\mathrm{n}}\right)$ as function of SAN 31 content in the PMMA/SAN 31 binary and ternary blends with MGE 1, for injection molded samples at $240^{\circ} \mathrm{C}$

previous authors. Therefore, it might be expected to observe an immiscible SAN 31/ MGE 1 blend.

SAN 24/PBT nanoblends were obtained by melt mixing and injection molded, as result the TEM micrographs are shown in Figure 7. However, it was necessary to use MGE 2 as compatibilizer to reduce the PBT phase average particle size as shown in Figure 7b. MGE 2 copolymer is a reactive compatibilizer which has epoxy functional groups to react in situ mainly with $\mathrm{COOH}$ end groups from PBT molecules during the melt mixing. The grafted PBT-
MGE molecules have segments which interact with both SAN 24 and PBT phases in the SAN 24/PBT blends and may diffuse to the interfacial region, thereby reducing its interfacial energy [26]. The average particle size for the SAN 24/PBT 90/10 blends obtained from the histograms in Figure $7 \mathrm{a}$ is $160 \pm 67 \mathrm{~nm}$, while addition of MGE 2 has reduce it to $101 \pm 45 \mathrm{~nm}$, obtained from Figure $7 \mathrm{~b}$. MGE 2 has shown a good efficiency to decrease the interfacial tension for the SAN 24/PBT blend, as well as, to prevent coalescence between the disperse particles. The reduction of the interfacial energy due to the presence of MGE 2 is expected to decrease the particle size as predicted by Equation (4). The evaluation of the interfacial tension for SAN 24/PBT blends was done from its viscoelastic properties, such as, dynamic modulus and relaxation time spectrum, obtained through dynamic rotational rheometry. The SAN 24/PBT blends interfacial tension is shown in Table 7 using two different models, Choi and Schowalter [35] and Palierne [36], respectively. A significant decrease in the interfacial tension can be observed by using the reactive compatibilizer MGE 2 in the SAN 24/PBT blends. That occurs when both methods are used to obtain it, as well as, both model to estimate it. That may be one of the reasons for the reduction in the disperse phase parti- 

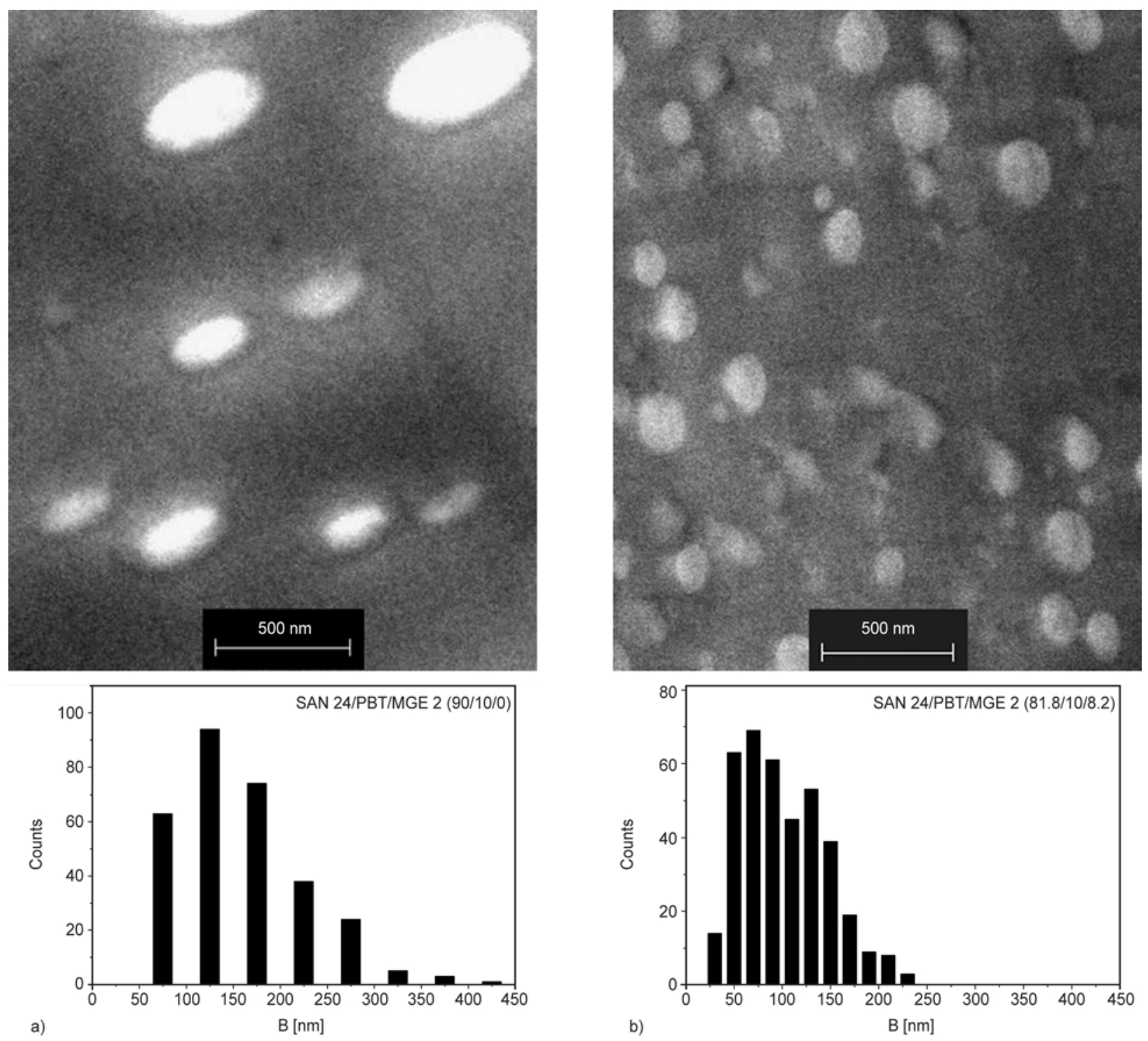

Figure 7. TEM micrographs and particle size distribution histograms for melt mixed SAN 24/PBT/MGE 2 blends, as extruded: (a) $90 / 10 / 0$; (b) $81.8 / 10 / 8.2$

Table 7. SAN/PBT blends interfacial energy measured by rotational rheometry

\begin{tabular}{|l|c|c|c|c|}
\hline \multirow{2}{*}{ Blends } & \multicolumn{2}{|c|}{$\begin{array}{c}\text { Interfacial energy } \\
\text { based on G' } \\
\text { [mN/m] }\end{array}$} & \multicolumn{2}{|c|}{$\begin{array}{c}\text { Interfacial energy } \\
\text { based on G* } \\
\text { [mN/m] }\end{array}$} \\
\cline { 2 - 5 } & Choi & Palierne & Choi & Palierne \\
\hline $\begin{array}{l}\text { SAN 24/PBT } \\
(90 / 10)\end{array}$ & 2.36 & 3.26 & 4.72 & 6.51 \\
\hline $\begin{array}{l}\text { SAN 24/PBT/MGE } \\
(88.1 / 10 / 8.2)\end{array}$ & 1.60 & 1.66 & 1.47 & 1.52 \\
\hline
\end{tabular}

$G^{\prime}$ : dynamic shear modulus;

$G^{*}$ : complex shear modulus

cle size in those blends. However, the coalescence effect can occur simultaneously with the reduction in interfacial tension which can leave to an increase in particle size. On the other hand, as the amount of PBT phase is decreased in the SAN 24/PBT/MGE 2 blends there is lower probability for the occurrence of coalescence.

Figure 8 shows evidences of the coalescence prevention as PBT content is reduced in the SAN 24/ PBT blends. The average particle size drops to values lower than $100 \mathrm{~nm}$. The average particle size for lower PBT disperse phase content was $68 \pm 27$ and $91 \pm 37 \mathrm{~nm}$, respectively, as observed in Figure 8a and 8 b. For those SAN 24/PBT compositions it was possible to obtain blends with smaller disperse particle size within the nanoscale. Coalescence effect depends basically on two parameters: number of particle collisions and the ability of a matrix film between two disperse particles to be drained out. The number of particle collisions is proportional to the square of disperse phase content and inversely 

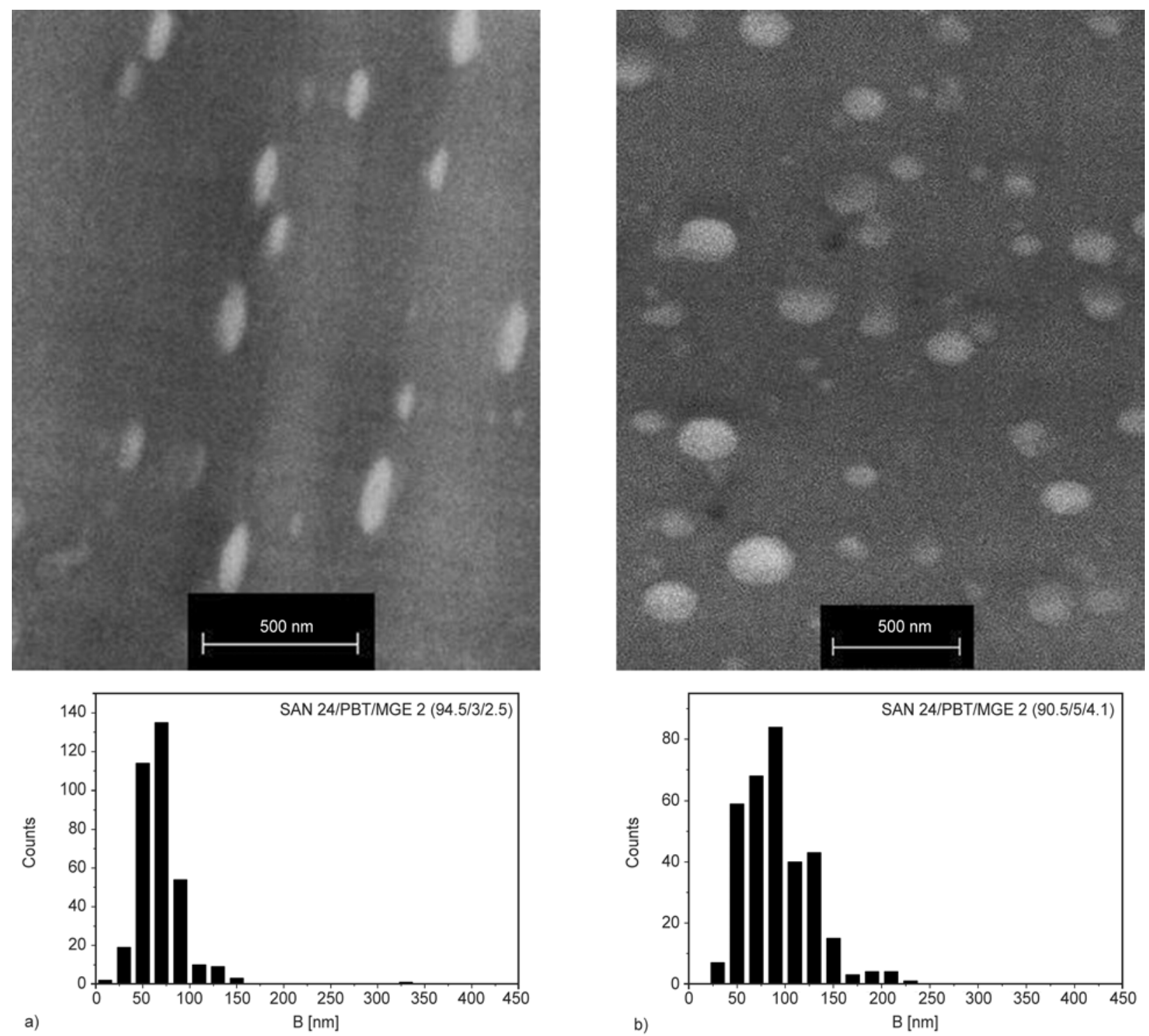

Figure 8. TEM micrographs and particle size distribution histograms for melt mixed SAN 24/PBT/MGE 2 blends, as extruded: (a) $94.5 / 3 / 2.5$; (b) $90.9 / 5 / 4.1$

proportional to the particle size, while the ability to drain out depends on the interfacial tension and it is inversely proportional to the matrix viscosity [37]. For lower interfacial tension values and viscosity ratio between disperse phase and matrix there is less chance to the matrix film between particles to be drained and as consequence there is coalescence suppression. From Figure 5 it is possible estimate the viscosity ratio $n_{\mathrm{r}}$ for SAN 24/PBT blends. For very low shear rates the PBT viscosity is smaller than SAN 24 viscosity. As the shear rate is increased to higher values PBT viscosity becomes closer to the SAN 24 viscosity. For very high shear rate PBT has higher viscosity than SAN 24. On the other hand, the $\mathrm{SAN} /(\mathrm{PBT}+\mathrm{MGE})$ viscosity is higher than SAN 24 viscosity at any shear rate. Both SAN 24/PBT and SAN 24/(PBT/MGE 2) blends were melt mixed in the twin screw extruder at 140 and $200 \mathrm{rpm}$. The lowest shear rate for both screw speed were calculated in the conveying screw section as 43 and $60 \mathrm{~s}^{-1}$, respectively. On the other hand, the maximum shear rates were calculated as 930 to $1330 \mathrm{~s}^{-1}$, respectively, in the kneading blocks screw sections [33]. Considering that drop breaking mostly occurs in the kneading blocks screw sections with higher shear rates, the viscosity ratio is close to 1 for the SAN 24/ PBT blend and is 1.8 for the SAN 24/(PBT+MGE 2), as observed in Table 8.

According to Equation (4) the PBT particle size $D$ can be estimated as shown in Table 9, where several values for $D$ were calculated for different shear rates and for interfacial tension obtained by different models from Table 7. The estimated particle size for tension for Palierne model and an increase in the 
Table 8. Capillary viscosity for SAN, PBT and PBT/MGE and viscosity ratio for their blends

\begin{tabular}{|c|c|c|c|c|c|}
\hline \multirow{2}{*}{$\begin{array}{c}\text { Shear rate } \\
\qquad\left[\mathbf{s}^{-1}\right]\end{array}$} & \multicolumn{3}{|c|}{$\begin{array}{c}\text { Capillary viscosity } \\
{[\mathrm{Pa} \cdot \mathrm{s}]}\end{array}$} & \multicolumn{2}{|c|}{ Viscosity ratio } \\
\hline & SAN 24 & PBT & PBT+MGE 2 & $\frac{\eta_{\mathrm{PBT}}}{\eta_{\mathrm{SAN} 24}}$ & $\frac{\eta_{\text {PBT }+ \text { MG 2 }}}{\eta_{\text {SAN 24 }}}$ \\
\hline 43 & 999 & 388 & 1607 & 0.4 & 1.6 \\
\hline 60 & 755 & 327 & 1229 & 0.4 & 1.6 \\
\hline 930 & 80 & 82 & 144 & 1.0 & 1.8 \\
\hline 1330 & 60 & 68 & 109 & 1.1 & 1.8 \\
\hline
\end{tabular}

Table 9. $\mathrm{PBT}$ and $\mathrm{PBT}+\mathrm{MGE}$ particle size estimated at different shear rates and interfacial tensions for SAN 24/PBT and SAN 24/(PBT+MGE 2) blends and obtained from TEM

\begin{tabular}{|c|c|c|c|c|c|c|c|}
\hline \multirow{3}{*}{$\begin{array}{c}\text { Shear rate } \\
\quad\left[\mathrm{s}^{-1}\right]\end{array}$} & \multirow{3}{*}{$\begin{array}{c}\text { Shear stress, } \\
\dot{\gamma} \eta_{\mathrm{m}} \\
{[\mathrm{Pa}]}\end{array}$} & \multicolumn{2}{|c|}{ Viscosity ratio } & \multicolumn{4}{|c|}{$\begin{array}{c}\text { Estimated particle size, D } \\
{[\mathrm{nm}]}\end{array}$} \\
\hline & & \multirow{2}{*}{$\frac{\text { PBT }}{\text { SAN 24 }}$} & \multirow{2}{*}{$\frac{(\text { PBT }+ \text { MGE 2) }}{\text { SAN 24 }}$} & \multicolumn{2}{|c|}{$\begin{array}{c}\text { PBT } \\
\text { Disperse phase }\end{array}$} & \multicolumn{2}{|c|}{$\begin{array}{l}\text { (PBT+MGE 2) } \\
\text { Disperse phase }\end{array}$} \\
\hline & & & & Choi $^{\mathrm{a}}$ & Palierne ${ }^{a}$ & Choi $^{\mathbf{a}}$ & Palierne $^{a}$ \\
\hline 930 & 74400 & 1.0 & 1.8 & 127 & 177 & 141 & 146 \\
\hline 1330 & 79800 & 1.1 & 1.8 & 128 & 179 & 132 & 140 \\
\hline \multicolumn{4}{|c|}{$\begin{array}{c}\text { SAN 24, PBT and (PBT+MGE 2) } \\
\text { Blends composition }\end{array}$} & \multicolumn{4}{|c|}{$\begin{array}{l}\text { Average particle size }[\mathrm{nm}] \\
\text { Measured from TEM }\end{array}$} \\
\hline \multicolumn{2}{|c|}{$[w t \% / w t \%]$} & \multicolumn{2}{|c|}{ [rpm] } & $\mathbf{B}^{\mathbf{b}}$ & $D_{n}{ }^{b}$ & $\mathbf{B}^{\mathbf{b}}$ & $D_{n}{ }^{b}$ \\
\hline \multicolumn{2}{|c|}{$\begin{array}{l}\text { SAN 24/PBT } \\
(90 / 10)\end{array}$} & \multicolumn{2}{|c|}{200} & $160 \pm 67$ & $227 \pm 99$ & \multicolumn{2}{|c|}{-} \\
\hline \multicolumn{2}{|c|}{$\begin{array}{c}\text { SAN 24/(PBT/MGE 2) } \\
94.5 / 3 / 2.5)\end{array}$} & \multicolumn{2}{|c|}{200} & \multicolumn{2}{|c|}{-} & $68 \pm 27$ & $104 \pm 42$ \\
\hline \multicolumn{2}{|c|}{$\begin{array}{c}\text { SAN 24/(PBT/MGE 2) } \\
(90.9 / 5 / 4.2)\end{array}$} & \multicolumn{2}{|c|}{200} & \multicolumn{2}{|c|}{-} & $91 \pm 37$ & $111 \pm 42$ \\
\hline \multicolumn{2}{|c|}{$\begin{array}{c}\text { SAN 24/(PBT/MGE 2) } \\
(90.9 / 5 / 4.2)\end{array}$} & \multicolumn{2}{|c|}{140} & \multicolumn{2}{|c|}{-} & $58 \pm 20$ & $86 \pm 31$ \\
\hline \multicolumn{2}{|c|}{$\begin{array}{c}\text { SAN 24/(PBT/MGE 2) } \\
(81.8 / 10 / 8.2)\end{array}$} & \multicolumn{2}{|c|}{200} & \multicolumn{2}{|c|}{-} & $101 \pm 45$ & $124 \pm 45$ \\
\hline
\end{tabular}

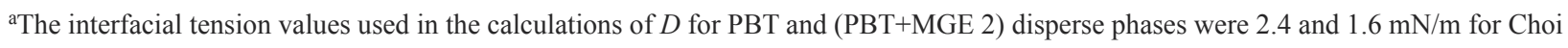
model and 3.3 and $1.7 \mathrm{mN} / \mathrm{m}$ for Palierne model, respectively.

${ }^{\mathrm{b}} B$ was measured as the smaller axis of the elliptical shape of most of the disperse particles. $D_{\mathrm{n}}$ was calculated as the equivalent average diameter of the particles based on their areas.

viscosity ratio for higher shear rates, as observed in Table 8 . The reduction in the particle size by using the Palierne model for compatibilized blends is due to the strong reduction in interfacial tension which overcomes an increase in the viscosity ratio by considering Equation (4). On the other hand, the reduction in the interfacial tension for the compatibilized blends using Choi model it was not enough to allow enough reduction in the estimated particle size, as shown in Table 9. For all estimated values no one has shown particle size below $100 \mathrm{~nm}$.

The particle dimensions measured for the SAN 24/ PBT blends are well above the ones for SAN 24/ (PBT+MGE 2). By considering the smaller dimension $B$ any of the SAN 24 blends most of them has shown average values lower than $100 \mathrm{~nm}$ within the range of nano particles. Although, the average equiv- alent diameter $D_{\mathrm{n}}$ has shown values above $100 \mathrm{~nm}$ for most compatibilized blends their dimension are smaller than the estimated ones. One of the main reasons to show $D_{\mathrm{n}}$ lower than predicted one is that the component (PBT+MGE 2) has reduced the possibility to occur coalescence within the evaluated shear rates. The estimation done by Equation (4) does not take in account the coalescence effect. The grafted PBT-g-MGE molecules besides reducing the interfacial tension have hindered the coalescence among the disperse phase particles.

\section{Conclusions}

Nanostructured polymer blends based on SAN copolymers have been obtained. The window of miscibility was obtained for both PMMA/SAN and SAN/PBT blends. For PMMA/SAN blends the range 
of AN content to have miscible blends has been found between 13 and $27.1 \mathrm{wt} \%$, while for SAN/ PBT blends the range was found between 17.8 and 21.9 AN wt\%. By chosen SAN copolymers containing AN just above the window upper limit it was possible to obtain Immiscible blends. SAN copolymer with $24 \mathrm{AN}$ wt $\%$ was chosen for PMMA/SAN immiscible blends, while a SAN with $31 \mathrm{AN}$ wt $\%$ was chosen for SAN/PBT as well as immiscible blends. The disperse phase particle size was estimated for those blends using Wu equation. The experimentally measured particle size was found within the range of the estimated values. The use of acrylic compatibilizers has helped to obtain particle size within the nanoscale by strongly reducing interfacial tension.

\section{Acknowledgements}

The authors would like to thank BASF, UNIGEL, SABIC Innovative Plastics and Sheet Cril by providing SAN, PMMA, PBT and MMA, respectively. The acknowledgement should also be extended to CNPq and FAPESP, Brazilian foundations by providing the fellowships.

\section{References}

[1] Hu G-H., Cartier H., Plummer C.: Reactive extrusion: Toward nanoblends. Macromolecules, 32, 4713-4718 (1999). DOI: $10.1021 / \mathrm{ma981924y}$

[2] Gallego R., García-López D., Merino J. C., Pastor J. M.: The effect of montmorillonite and compatibilizer quantities on stiffness and toughness of polyamide nanoblends. Polymer International, 59, 472-478 (2010). DOI: $10.1002 /$ pi.2724

[3] Sundararaj U.: Micro- and nanostructured multiphase polymer blend systems: Phase and interfaces. in 'Phase morphology development in polymer blends: Processing and experimental aspects' (eds.: Harrats C., Thomas S., Groeninckx G.) Taylor and Francis, London, 133164 (2006).

[4] Nam S. Y., Dorgan J. R.: Non-equilibrium nanoblends via forced assembly for pervaporation separation of benzene from cyclohexane: UNIFAQ-FV group contribution calculations. Journal of Membrane Science, 306, 186-195 (2007).

DOI: $10.1016 /$ j.memsci.2007.08.047

[5] Segal E., Tchoudakov R., Narkis M., Siegmann A., Wei Y.: Polystyrene/polyaniline nanoblends for sensing of aliphatic alcohols. Sensors and Actuators B: Chemical, 104, 140-150 (2005). DOI: $10.1016 /$ j.snb.2004.05.002
[6] Alam T. M., Otaigbe J. U., Rhoades D., Holland G. P., Cherry B. R., Kotula P. G.: Nanostructured polymer blends: Synthesis and structure. Polymer, 46, 1246812479 (2005).

DOI: $10.1016 /$ j.polymer.2005.10.079

[7] Ji Y., Ma J., Liang B.: A novel approach to the preparation of nano-blends of PPO/PS/PA6. Polymer Bulletin, 54, 109-115 (2005). DOI: $10.1007 / \mathrm{s} 00289-005-0366-5$

[8] Okeowo O., Nam S. Y., Dorgan J. R.: Nonequilibrium nanoblend membranes for the pervaporation of benzene/cyclohexane mixtures. Journal of Applied Polymer Science, 108, 2917-2922 (2008).

DOI: 10.1002/app.27749

[9] Kotal M., Srivastava S. K., Paramanik B.: Enhancements in conductivity and thermal stabilities of polypyrrole/polyurethane nanoblends. The Journal of Physical Chemistry C, 115, 1496-1505 (2011).

DOI: $10.1021 / j p 1081643$

[10] Li Y., Shimizu H.: Morphological investigations on the nanostructured poly(vinylidene fluoride)/polyamide 11 blends by high-shear processing. European Polymer Journal, 42, 3202-3211 (2006).

DOI: $10.1016 /$ j.eurpolymj.2006.08.014

[11] Li Y., Shimizu H.: Fabrication of nanostructured polycarbonate/poly(methyl methacrylate) blends with improved optical and mechanical properties by highshear processing. Polymer Engineering and Science, 51, 1437-1445 (2011). DOI: $10.1002 /$ pen.21879

[12] Utracki L. A.: Polymer alloys and blends: Thermodynamics and rheology. Hanser, New York (1989).

[13] Paul D. R., Bucknall C. B.: Polymer blends: Formulation. Wiley, New York (2000).

[14] Fowler M. E., Barlow J. W., Paul D. R.: Effect of copolymer composition on the miscibility of blends of styrene-acrylonitrile copolymers with poly (methyl methacrylate). Polymer, 28, 1177-1184 (1987). DOI: 10.1016/0032-3861(87)90261-8

[15] Ranganathaiah C., Kumaraswamy G. N.: New method of determining miscibility in binary polymer blends through hydrodynamic interaction: The free volume approach. Journal of Applied Polymer Science, 111, 577-588 (2009). DOI: $10.1002 /$ app.29046

[16] Ren L., Zhang M. Y., Wang Y. R., Na H., Zhang H. X.: Investigation on the miscibility of the blends of poly (methyl methacrylate) and poly(styrene-co-acrylonitrile). Journal of Applied Polymer Science, 123, 292 298 (2012).

DOI: $10.1002 /$ app.34336

[17] Paul D. R., Barlow J. W.: A binary interaction model for miscibility of copolymers in blends. Polymer, 25, 487-494 (1984).

DOI: $\underline{10.1016 / 0032-3861(84) 90207-6}$ 
[18] Suess M., Kressler J., Kammer H. W.: The miscibility window of poly(methylmethacrylate)/poly(styrene-coacrylonitrile) blends. Polymer, 28, 957-960 (1987).

DOI: 10.1016/0032-3861(87)90169-8

[19] Higashida N., Kressler J., Inoue T.: Lower critical solution temperature and upper critical solution temperature phase behaviour in random copolymer blends: Poly(styrene-co-acrylonitrile)/poly(methyl methacrylate) and poly(styrene-co-acrylonitrile)/poly( $\varepsilon$-caprolactone). Polymer, 36, 2761-2764 (1995). DOI: $10.1016 / 0032-3861(95) 93654-5$

[20] Shimonai K., Higashida N., Ougizawa T., Inoue T., Rudolf B., Kressler J.: Studies on miscibility in homopolymer/random copolymer blends by equation of state theory. Polymer, 37, 5877-5882 (1996).

DOI: $10.1016 / \mathrm{S} 0032-3861(96) 00453-3$

[21] Larocca N. M., Ito E. N., Rios C. T., Pessan L. A., Bretas R. E. S., Hage. E. Jr: Effect of PBT molecular weight and reactive compatibilization on the dispersed-phase coalescence of PBT/SAN blends. Journal of Polymer Science Part B: Polymer Physics, 48, 2274-2287 (2010). DOI: $10.1002 /$ polb.22110

[22] Sundararaj U., Mackosco C. W.: Drop breakup and coalescence in polymer blends: The effects of concentration and compatibilization. Macromolecules, 28, 2647-2657 (1995).

DOI: $10.1021 / \mathrm{ma} 00112 \mathrm{a} 009$

[23] Wu S.: Formation of dispersed phase in incompatible polymer blends: Interfacial and rheological effects. Polymer Engineering and Science, 27, 335-343 (1987). DOI: $10.1002 /$ pen.760270506

[24] Li Y., Iwakura Y., Zhao L., Shimizu H.: Nanostructured poly(vinylidene fluoride) materials by melt blending with several percent of acrylic rubber. Macromolecules, 41, 3120-3124 (2008).

DOI: $10.1021 / \mathrm{ma} 7027402$

[25] Lumlong S., Kuboyama K., Chiba T., Oyama H. T., Ougizawa T.: Shear effect on morphology of poly(butylene terephthalate)/poly(styrene-co-acrylonitrile) blends. Journal of Macromolecular Science Part B: Physics, 43, 711-724 (2004).

DOI: $10.1081 / \mathrm{MB}-120030016$

[26] Hale W., Keskkula H., Paul D. R.: Compatibilization of PBT/ABS blends by methyl methacrylate-glycidyl methacrylate-ethyl acrylate terpolymers. Polymer, 40, 365-377 (1999).

DOI: $10.1016 / \mathrm{S} 0032-3861(98) 00189-\mathrm{X}$
[27] Borman W. F. H.: Molecular weight-viscosity relationships for poly(1,4-butylene terephthalate). Journal of Applied Polymer Science, 22, 2119-2126 (1978). DOI: 10.1002/app.1978.070220804

[28] Pohl H. A.: Determination of carboxyl end groups in polyester, polyethylene terephthalate. Analytical Chemistry, 26, 1614-1616 (1954).

DOI: $10.1021 / \mathrm{ac} 60094 \mathrm{a} 024$

[29] Chu J. H., Paul D. R.: Interaction energies for blends of SAN with methyl methacrylate copolymers with ethyl acrylate and $n$-butyl acrylate. Polymer, 40, 26872698 (1999).

DOI: $10.1016 / \mathrm{S} 0032-3861(98) 00499-6$

[30] Tokita N.: Analysis of morphology formation in elastomer blends. Rubber Chemistry and Technology, 50, 292-300 (1977).

DOI: $10.5254 / 1.3535144$

[31] Hong Z., Shaw M. T., Weiss R. A.: Effect of shear flow on the morphology and phase behavior of a near-critical SAN/PMMA blend. Macromolecules, 31, 62116216 (1998). DOI: $10.1021 / \mathrm{ma} 980637 \mathrm{r}$

[32] Ito E. N., Ueki M. M., Bretas R. E. S., Hage Junior E.: Interfacial tension of PBT/SAN blends by the drop retraction method. Materials Research, 11, 165-169 (2008).

DOI: $10.1590 /$ S1516-14392008000200009

[33] Beatrice C. A. G., Branciforti M. C., Alves R. M. V., Bretas R. E. S.: Rheological, mechanical, optical, and transport properties of blown films of polyamide 6/residual monomer/montmorillonite nanocomposites. Journal of Applied Polymer Science, 116, 3581-3592 (2010). DOI: $10.1002 / a p p .31898$

[34] Gan P. P., Paul D. R.: Interaction energies for blends based on glycidyl methacrylate copolymers. Polymer, 35, 3513-3524 (1994).

DOI: 10.1016/0032-3861(94)90917-2

[35] Choi S. J., Schowalter W. R.: Rheological properties of nondilute suspensions of deformable particles. Physics of Fluids, 18, 420-427 (1975).

DOI: $10.1063 / 1.861167$

[36] Palierne J. F.: Linear rheology of viscoelastic emulsions with interfacial tension. Rheologica Acta, 29, 204-214 (1990). DOI: $10.1007 / \mathrm{BF} 01331356$

[37] Gramespacher H., Meissner J.: Interfacial tension between polymer melts measured by shear oscillations of their blends. Journal of Rheology, 36, 1127-1141 (1992).

DOI: $10.1122 / 1.550304$ 